\title{
DO THE VIRTUAL COMMUNITIES MATCH THE REAL ONES? (COMMUNITARIAN PERSPECTIVE)
}

\begin{abstract}
The paper traces the concept of 'responsive' (real) community as defined by communitarians. Responsive community is defined as a morally valued way of life characterized by a shared set of values. This concept of community embodies the idea that human beings are fundamentally related to each other through social bonds and value consensus that enable stable relationships among the members. However, a new kind of community - the virtual/online community - has appeared due to the modernization and information technology development in society. Individuals interacting online are often loosely linked by specialized instrumental ties and the boundaries of virtual/online communities seem to be fluid and association among members ephemeral. From the communitarian perspective of a community responsive to the needs of its members as well as demands of society, the author attempts to find out if the virtual communities still meet the conditions of 'real' communities.
\end{abstract}

Keywords: Responsive community, virtual community, shared values, communitarianism.

\section{Introduction}

Nowadays, there are many discussions regarding virtual or online communities among scholars as well as wide public. They are mostly discussing the issue of privacy protection, individual freedom, openness, responsibility, equality, truthfulness and morals of such a way of communication and socializing compared with the real off-line social relationships. Based on the communitarian concept and understanding of community, I will try to find the answer to the question of How much the virtual communities match the real ones in the sense of their main features and requirements. On the one hand, many scholars, e. g. Postill [1], Yuan [2], Wittel [3] etc. are now concerned that voluntary, fluid and ephemeral social relationships online do not bear out the deeply embedded human interdependence embodied in the concept of traditional community, despite its normative appeal, and that human relations in computermediated communities cannot be as intimate, strong, and affect-laden as in real communities. On the other hand, initial research on online community showed many cases of intense feelings of solidarity, empathy and support that people generate when interacting in virtual environments, which relates well to the emotional and normative dimensions of the community concept, and therefore helped legitimize the conception of (digitally) networked communication as a "community" [4, p. 4]. Following various network analyses, it seems that online communities have similar structural characteristics. In fact, the very term 'network' has come to signify an amorphous, transient and fluid social construction [5]. Elements such as values, beliefs, meaning, and motivation, which are crucial for community formation and integration, are either treated as confounding variables or as dependent on structure [4, p. 7]. Therefore, we suppose that virtual or online communities must somehow live up to the accomplishments of the real ones at least partially.

\section{Communitarian concept of a (real) community}

Nowadays communities (as Communitarians define them) are typical for a number of elements of heterogeneity. They are more diverse, adaptable and promote individual freedom and responsibility in the context of obligations to the group. Current communities are in continual active contacts with the outside world and their values are accessible to all. They try to constantly present and emphasize the common culture, and consciously promote the values and standards that maintain their integrity. In this sense they can be defined as certain "webs of social relations that encompass shared meanings and above all shared values" [6, p. 24] and at the same time

\footnotetext{
* Jarmila Jurova

Department of Journalism, Faculty of Arts, Constantine the Philosopher University, Nitra, Slovakia

E-mail: jjurova@ukf.sk
} 
as "complex wholes that guide individual activity and sustain identity" [7, p. 175]. Hence, a group can be understood as community provided that it embraces a wide range of interests and activities that take the person as a whole into account, and that there exist certain common responsibilities and common culture within it. People share set of values and obligations which are based on the interdependence and the consciousness of common identity.

According to Etzioni community has specific features: "First, communities provide bonds of affection that turn groups of people into social entities resembling extended families. Second, they transmit a shared moral culture (a set of shared social meanings and values that characterize what the community considers virtuous versus unacceptable behaviour) from generation to generation, as well as reformulating this moral framework day by day" [8, p. 15]. Communities are therefore not only aggregates of persons acting as free players, but also units that have their own identity and purpose and can act as separate units and wholes. Another notable feature of the community from Etzioni's point of view is the "relatively high level of sensitivity" [9, p. 5]. It means that the real community is not considered a social unit that oppresses their members and responds to their false needs. As Selznick states, normal communities take account of how people actually live, and want to live, not only how we want them to live [10, 11 - 12]. In this context, communitarians appeal to the need to create interconnected networks of communities because people are the members of several communities that provide them with support on various levels and in different contexts (family, school, workplace, settlement, town, church, youth organizations, various interest groups etc.). Some of them are called "constitutive" [13, p. 103] in the life of an individual as these are the communities that constitute people as individuals in large extent. They answer the basic question Who am I? and in Western culture they are often related to the place in a geographical sense - communities of place [14] as well as communities of memory or psychological communities (e. g. religious communities) [15].

Community must show some degree of integrity and consistency, otherwise it is not able to act in terms of shared values and goals. Integrity of the community must not stifle its internal diversity, the possibility of internal opposition, and the possibility of creating subcommunities; but it should rather promote a philosophy of pluralism. At the same time, diversity must not undermine the integrity of the community, so there must work certain institutional arrangements, agreements that reduce.

Another defining character of the community, and perhaps the most important, is a "reasonable base of shared values" [16, p. 170], which should be anchored in the form of laws and rules, but also in customs and traditions: These values should present shared vision and understanding of the common good and the future of the community and they are protected by community and its members together with the respect and active promotion of the ideals of freedom, justice, equality and human dignity.

Moreover, a good community supports climate of cooperation, requiring respect for individual differences and for the value of personal integrity. Its members must be also aware of interdependence, responsibility and the need for mutual trust. In order to establish the identity associated with certain community, active participation of community members in common tasks and the life of community is required. However, to be realistic, it would be naive to require the same level of participation from every member of community.

Healthy community constantly creates its own morals and validates its values and ideals; it has a working institutional system enabling effective communication not only within the community but also outward to other communities and to society in general. In a democratic society communities cannot be repressive, intolerant or immoral, but they must be responsive to the needs of their members and open to justified changes. In this sense "responsiveness", sensitivity or accessibility can be perceived as the cardinal feature of communities $[9$, p. 2-3].

\section{Virtual (online) community and its comparison with a real community}

It is evident that the discussions on the comparison of real (offline) and virtual (online) communities usually start with some scepticism about the question whether virtual communities match the real ones. Real and virtual communities each have their own advantages as well as their own weaknesses. From the communitarian perspective described above we will investigate what real communities can do that virtual communities cannot, and vice versa.

We suppose that virtual communities are "communities" first and "virtual" second. The technological development and the Internet have influenced the ways of communication in many spheres [17, p. 34]. Moreover, IT initiates the development of professional and scientific communities which enable new possibilities of research, alternative outcomes and wider public discussion [18]. As Evans claims the space the Internet provides is both private and communal [19], so people can sustain intimate, personal encounters as well as open, accessible forums. Individuals can learn about each other and community can flourish, and, it definitely plays an important role in the way we construct our most meaningful interpersonal relationships today. We also suggest that the main purpose of real as well as virtual communities nowadays is basically the same - it is communication and interaction 
creating lasting relationship between people and allowing them to follow a shared set of values.

But in what way does the communication in virtual communities differ from the communication in real communities? Members of virtual communities do not necessarily live in the same region, so they do not meet or use face-to-face communication. However, they still can develop close relationships thanks to the communication via modern technologies. Moreover, as virtual community does not necessarily require such a personal communication because people do not have to see each other, they may even feel more self-confident while meeting new people, which is obviously helpful for future communication in real communities. Via virtual communities, people can bond without being in close proximity either spatially or temporarily, so communities can evolve even across national borders and time zones [20, p. 295]. They can encompass individuals who are homebound because of illness, age, or handicap, so as a result, for some people it is even easier to be a member of a virtual community than of a real community.

While from the communitarian point of view the concept of real community embodies the idea that human beings are fundamentally related to each other as 'whole persons' through social bonds [9] and value consensus that enable stable relationships among the members [10], individuals interacting online are often loosely linked by specialized instrumental ties and the boundaries of virtual communities are fluid and association among members ephemeral [21]. Virtual communities seem to be simply fluid aggregates of such networked individuals. Individualist attributes of the virtual community, such as voluntary association based on needs, clearly distinguish it from real communities with inherent normative structures nurturing organic orders [11]. According to Fernback [2, p. 49] "members of virtual communities speak of mutual respect and caring but demur at the notion of true closeness of the members". As Yuan [4] suggests, the metaphor of "community" in cyberspace is one of convenient togetherness without real responsibility. Hence, the concept of virtual community has become increasingly diluted as it evolves into a pastiche of elements that ostensibly "signify" community.

However, there are obviously certain differences between people constituting real communities and people constituting virtual communities. Real communities consist of people who live in the same territory, who may be of the same race, culture and religion, while virtual communities can consist of people of different nationality, colour of skin, culture or religion. People are united in virtual communities not by the common place of living, but they are united by common interests, ideas and beliefs above all. This is what communitarians call "shared values". And, "morality and values are integral parts of human communities - they are necessarily (by definition) socially embodied, not individually based" [12, p. 104].

There is another essential difference between real and virtual communities which we could call volitional choice. This means that the membership in virtual communities is much more voluntary than in the real communities as an individual member can terminate his or her membership in the virtual community conveniently and effortlessly - often simply by ending the navigation session and never returning to the virtual community's domain. This is not always possible in the case of real communities.

Some more advantages of virtual communities can be also identified. One of them is that online discussion groups or forums can accommodate many more individuals than offline meeting rooms can accommodate [20, p. 295]. Another advantage is that people can explore new relationships or even new identities online as they are not constrained by their physical appearance or off-line identity [20, p. 295]. The Internet as a new social space liberates people from social norms and enables them to cycle through identities for self-exploration and expression [22]. Online groups are often constructed in a way that allows high visibility of relational clues and mutual relationship monitoring.

New Communitarians suggest that virtual communities are really able to form their own norms and enable strong relationships among their members, which often supplement interaction of people in real communities [23]. And, what is more, they usually have developed moral norms, such as principles of generalized reciprocity and assistance: "Even in contexts of anonymity, which hinders social controls, virtual communities have developed tools that help enforce social norms. Informal social control by social exclusion is practiced to limit "flaming", the practice of posting or sending insults or inflammatory messages on the Internet" [24, p. 391]. Another aspect of virtual communities is often mentioned when compared to real communities - anonymity. In certain sense it can be understood as a form of privacy because it reduces visibility. Virtual forms of interaction allow the usage of alias and anonymity leads to "much more polarized, coarse, uncivil social platforms, often riddled with racist, sexist, homophobic and xenophobic expressions" [25, p. 430]. Although the communities on social webs allow the usage of "false names", whatever is written there, immediately appears on the hundreds or thousands of screens of other users [26]. On the other hand, virtual communities actually provide some of the elements of "real" communities such as the informal social controls limiting e. g. the role of the state, enabling peer governance to prevent disruptive behavior on the Internet, regarding when and who to connect with etc. However, in this virtual realm these controls also require visibility and hence limit users' privacy. Etzioni [25, p. 427] also suggests that 
such controls work best when people's identities online are connected to their offline identities (e.g. Facebook).

\section{Common features of real and virtual communities}

Karen Evans' study aims at various aspects of real and virtual communities that we consider relevant in the search for their common features and possible matches [19].

As mentioned above, responsiveness is one of the most important characteristics of communitarian understanding of community. Responsiveness to the needs of community members includes requirements such as openness, accessibility, effectivity, democratic principles etc.

Considering the question of openness and accessibility of virtual communities, Internet services are free or at least affordable in public places nowadays, however, this does not necessarily mean that everybody can or wants to use the access to cyberspace. There can be various barriers of potential members of virtual community due to language, technical skills or technology available. So the users must be motivated and able to find and enter the community that can be beneficial and useful for them.

Wellman [19] claims that people who find each other and converse on the Internet will engage in encounters which are more focused than those which take place in the physical world. They engage only in the communities of their real interest, so the conversation is meaningful and may be more effective and rewarding. In real communities (of place, psychological etc.) the contact is often unplanned and chaotic, which can be not desirable. On the other hand, in real life one contact can bring more benefits and may be more effective.

Taking democratic principles into consideration, it must be noticed that virtual communities are not controlled by one power and they are open to "new forms of social participation" [19] as well as to diverse ways of thinking, so they break any system of autocratic system management or any hierarchical order. What is more, they allow direct contact and communication between individuals without any mediating tools, which makes the virtual community democratic.

This is connected with the requirement of liberation within community. Virtual communities, as Wellman [19] argues, allow their members great freedom in the sense of making connection (as they are only limited by the access to the Internet or other technology) as well as great freedom of action (because they disengage people from the often rigid roles which are associated with ideas of household, neighbourhood, region or nation). However, we suggest that social relationships which have forged through this medium will prove to be fundamentally different from those which have not.

\section{Conclusion}

To conclude, it is evident that the "virtual world" is a different place from the real world. On the other hand, virtual communities as alternative spaces are definitely becoming as important to Internet users as their real-world communities. As the virtual world is taking power over the offline world, more and more people are connecting online, joining community that better understand them, sharing the same interest (MySpace, LinkedIn, online games etc.). Undoubtedly, there are many differences between virtual world and real life and between communication in virtual communities and real communities, but "the feeling and emotion are the same" [20]. We will probably have to get used to the idea that the word community is going to have to stretch to include groups of people who communicate socially and work cooperatively and never meet in the real world. It seems that real communities are better than virtual communities in communicating affect, identifying participants and holding them accountable, and in providing group feedback. However, virtual communities have many advantages as well. The good combination of virtual and real communities is probably able to overcome the weaknesses of each and combine many of the strengths of both.

\section{References}

[1] BAKARDJIEVA, M.: Virtual Togetherness: An Everyday-life Perspective. Media, Culture and Society, vol. 25, No. 3, 2003, 29-313. ISSN 0163-4437.

[2] FERNBACK, J.: Beyond the Diluted Community Concept: A Symbolic Interactionist Perspective on Online Social Relations. New Media \& Society, vol. 9, No. 1, 2007, 49-69. ISSN 1461-4448.

[3] POSTILL, P.: Localizing the Internet beyond Communities and Networks. New Media \& Society, vol. 10, No. 3, $2008,413-43$. ISSN 1461-4448.

[4] YUAN, E. J.: Community in Modern Societies: A Critique of "Online Community” in New Media Studies. New Media \& Society, vol. 15, No. 5, 2013, 1-32. ISSN 1461-4448. 
[5] WITTEL, A.: Toward a Network Sociality. Theory, Culture \& Society, vol. 18, No. 6, 2001, 51-76. ISSN 0263-2764.

[6] ETZIONI, A.: Old Chestnuts and New Spurs. A. Etzioni (ed.): New Communitarian Thinking. Persons, Virtues, Institutions, and Communities. Charlottesville and London: University Press of Virginia, 1995, 16-34. ISBN 9780813915647.

[7] SUllivAN, M. W.: Institutions as the Infrastructure of Democracy. A. Etzioni (ed.): New Communitarian Thinking. Persons, Virtues, Institutions, and Communities. Charlottesville and London: University Press of Virginia, 1995, 170-180. ISBN 9780813915647.

[8] ETZIONI, A.: The Third Way to a Good Society. London: Demos, 2000. ISBN 1-84180-030-9.

[9] ETZIONI, A.: The Responsive Community: A Communitarian Perspective. American Sociological Review, vol. 61, No. 1, 1996, 1-11. ISSN 0003-1224. Etzioni here states particular conditions of responsiveness.

[10] SELZNICK, P.: The Communitarian Persuasion. Washington, D. C.: Woodrow Wilson Center Press, 2002. ISBN 1-930365-06-3.

[11] KATZ, J. E., RICE, R. E, ACORD, S. et al.: Personal Mediated Communication and The Concept of Community in Theory and Practice. Kalbfleisch, P. (ed.): Communication Yearbook 28. Mahwah, NJ : Erlbaum, 2004, 315-371. ISBN 9781135608804.

[12] VALCO, M., KRALIK, R., BARETT, L.: Moral Implications of Augustine's Philosophical and Spiritual Journey in his Confessions. Communications - Scientific Letters of the University of Zilina, vol. 17, No. 2, 2015, 103-108. ISSN 1335-4205.

[13] BELL, D.: Communitarianism and its Critics. Oxford: Clarendon Press, 1993. ISBN 0-19-827922-1.

[14] Mostly it is a place associated with home, the place where we have family, relatives, friends and neighbours. One of the examples of community of place is a town: “...a town is the space in which we are created, a space that shapes us and that is our living space...” In DEBNAR, M.: Between an Idea and Image. Selected Chapters on Philosophy of Literature (in Slovak), Bratislava: Ars Poetica, 2013, 129. ISBN 978-80-89283-66-8.

[15] Some authors emphasize that religious communities have the potential to "connect the dots", so to speak, to link the shattered pieces within the lives of individuals and put together (socially) the seemingly random mosaic of contradictory and competing desires and fears of human subjects into a community with a shared vision, ethos, and purpose. See e.g.: VALCOVA, K., PAVLIKOVA, M., ROUBALOVA, M.: Religious Existentialism as a Counter Measure to Moralistic Therapeutic Deism. Communications - Scientific Letters of the University of Zilina, vol. 18, No. 3, 2016, 98-104. ISSN 13354205 and KONDRLA, M., PAVLIKOVA, M.: From Formal Ethics to Existential Ethics. European J. of Science and Theology, vol. 12, No. 3, 2016, 101-111. ISSN 1841-0464.

[16] GARDNER, J.: Building a Responsive Community. A. Etzioni (ed.): Rights and the Common Good. The Communitarian Perspective, New York: St. Martin's Press, 1995, 167-178. ISBN 0-312-08968-6. For the possible set of shared values typical for current Western culture see also PALITEFKA, J.: Western Universalism in the Contemporary Worlds. InterNaciones, vol. 4, No. 10, 2015, 75-85. ISSN 2007-9680.

[17] HODINKOVA, D.: The Usage of Marketing Communication Digital Tools in Social Marketing (in Slovak). In Marketing identity 2015: Digitalny marketing \& Digitalny spotrebitel: zbornik z medzinarodnej vedeckej konferencie organizovanej v Kongresovom centre SAV na Smolenickom zamku, november 2015. Trnava: UCM, 2015, 33-42. ISBN 978-80-8105-778-6.

[18] GOGORA, A.: Digital Humanities and Philosophy - the Problem of Digital Research (in Slovak). World Literature Studies, vol. 25, No. 3, 2016. ISSN 1337-9275.

[19] EVANS, K.: The Significance of Virtual Communities, [online], The J. of Social Issues. Special Issue on 'The Futures of Community', vol. 2, No. 1, 2004. ISSN 1474-2918 Available on the Internet: http://www.whb.co.uk/socialissues/vol2ke. htm\#KarenEvans [28/08/2016].

[20] ETZIONI, A., ETZIONI, O.: Are 'Virtual' Communities Similar to or Different from 'Real' Communities? [online], Science, vol. 277, No. 5324, 1997. ISSN 1095-9203. Available on the Internet: https://cti09.wikispaces.com/ Are+\%27Virtual\%27+Communities+similar+to+or+different+from+\%27Real\%27+Communities\%3F [28/08/2016].

[21] JOHNSON, C. M.: A Survey of Current Research on Online Communities of Practice. The Internet and Higher Education, vol. 4, No. 1, 2001, 45-60. ISSN: 1096-7516.

[22] TURKLE, S.: Cyberspace and Identity. Contemporary Sociology, vol. 28, No. 6, 1999, 643- 648. ISSN 00943061.

[23] ETZIONI, A., ETZIONI, O.: Face-to-Face and Computer-Mediated Communities. A Comparative Analysis. The Information Society, vol. 15, No. 4, 1999, 241-248. ISSN 0197-2243.

[24] WALL, D. S., WILliamS, M.: Policing Diversity in Virtual Communities. Criminology \& Criminal Justice, vol. 7, No. 4, 2007, 391-415. ISSN 17488958.

[25] ETZIONI, A.: A Liberal Communitarian Conception of Privacy. J. Marshall J. of Computer \& Information Law, vol. 29, No. 3, 2012, 419-461. ISSN 1078-4128.

[26] DEBNAR, M.: The Disappearance of the Author and Meaning Making (in Slovak). World Literature Studies, vol. 25, No. 3, 2016, ISSN 1337-9275. 